Article

\title{
Assessing the Oenological Potential of Nakazawaea ishiwadae, Candida railenensis and Debaryomyces hansenii Strains in Mixed-Culture Grape Must Fermentation with Saccharomyces cerevisiae
}

\author{
Niel van Wyk ${ }^{1,2}$, Isak S. Pretorius ${ }^{1}$ (D) and Christian von Wallbrunn ${ }^{2, *}$ \\ 1 ARC Centre of Excellence in Synthetic Biology, Department of Molecular Sciences, Macquarie University, \\ Sydney, NSW 2109, Australia; niel.vanwyk@mq.edu.au (N.v.W.); sakkie.pretorius@mq.edu.au (I.S.P.) \\ 2 Department of Microbiology and Biochemistry, Hochschule Geisenheim University, \\ 65366 Geisenheim, Germany \\ * Correspondence: christian.wallbrunn@hs-gm.de
}

Received: 20 April 2020; Accepted: 3 May 2020; Published: 7 May 2020

check for updates

\begin{abstract}
Recently, there has been a growing interest in the role of non-Saccharomyces yeast (NSY) as a coculturing partner with Saccharomyces cerevisiae during grape must fermentation. We investigated three new strains, namely Nakazawaea ishiwadae, Candida railenensis and Debaryomyces hansenii, for their oenological potential in mixed-culture micro-vinifications with S. cerevisiae Vin13 using Muscaris grape must. None of the NSY strains impeded the fermentation performance as all the mixed-culture experiments finished at the same time. Coculturing with $N$. ishiwadae yielded significantly higher concentrations of ethyl and acetate esters in the final wine product. Apart from higher acetic acid levels, wines produced with $C$. railenensis and D. hansenii yielded much lower esters concentrations. The concentrations of certain terpenes and norisoprenoids were also significantly modulated in the mixed-culture fermentations. This study reveals the rarely reported species of $N$. ishiwadae as a promising coculturing partner for increasing aroma-active compounds in a wine.
\end{abstract}

Keywords: non-Saccharomyces yeast; Nakazawaea ishiwadae; aroma; mixed-culture fermentations; wine yeast

\section{Introduction}

Since the second half of the 1960s, commercial starter cultures of Saccharomyces cerevisiae wine yeast strains became available and soon afterwards were widely adopted among the winemaking community. Using starter cultures allowed for a far more reliable fermentation with far fewer reports of stuck or sluggish fermentations [1]. Different kinds of wine yeast were also developed for specific outcomes and varieties of grapes; yet, they all belonged to the Saccharomyces genus. A large-scale genomic analysis of different wine yeast revealed that many commercial yeast are, from a genomic perspective, remarkably similar [2], and it was suggested that breeding with S. cerevisiae strains outside of the "wine clade" would be necessary in order to expand on the winemaking capabilities of wine yeast, including to develop on the breath of possible flavor profiles for wines prepared using defined cultures.

Alternatively, wine yeast researchers have, for the past twenty years, started to investigate the use of non-Saccharomyces yeasts (NSY; also called non-conventional yeasts) as starter culture co-partners with S. cerevisiae. Several of these investigations resulted in the successful coculturing of Saccharomyces and non-Saccharomyces and yielded wines with improved qualities. Examples of improved characteristics included a marked decrease in ethanol levels, increased release of varietal 
aroma compounds, favorable acid modulation, increased aroma complexity and higher polysaccharide presence as a result of the coculturing of an NSY with S. cerevisiae [3-6].

Some of the coculturing experiments led to the availability of several commercial NSY starter cultures. These include strains of Lachancea thermotolerans, Metschnikowia pulcherrima, Pichia kluyveri, Schizosaccharomyces pombe, Starmerella bacillaris and Torulaspora delbrueckii. All of these NSY were isolated from oenological environments and through various trials have been shown to provide consistent improvements to various aspects of wine. However, there are many other NSY yeasts isolated from wine that are yet to be fully explored in terms of their compatibility with Saccharomyces wine yeasts and their potential contribution to wine quality $[5,7,8]$. In the context of ongoing assessments of the oenological potential of NSY yeasts, some progress have been made with experiments using species of Issatchenkia $[9,10]$ and Hanseniaspora [11,12]. Coculturing studies with selected strains of both of these genera indicated that they have the capacity to contribute positively to the final wine; however, these NSY yeasts are yet to make it to the market.

In this study, we explored the utility of three NSY yeasts with limited knowledge about their co-fermenting contributions-Nakazawaea ishiwadae, Candida railenensis and Debaryomyces hansenii-in mixed-culture Muscaris grape must fermentations.

\section{Materials and Methods}

\subsection{Grape Must}

Muscaris grapes from the 2018 vintage harvested in a vineyard of the Hochschule Geisenheim University in the Rheingau wine region of Germany were used for micro-vinifications. The grape juice's starting sugar content was $215.4 \mathrm{~g} / \mathrm{L}(105.3 \mathrm{~g} / \mathrm{L}$ glucose and $110.1 \mathrm{~g} / \mathrm{L}$ fructose) with the two major wine acids, namely tartaric acid and malic acid, being $4.7 \mathrm{~g} / \mathrm{L}$ and $3.8 \mathrm{~g} / \mathrm{L}$, respectively. The must's primary amino acid content was assayed using the NOPA (nitrogen by o-phthaldialdehyde) method [13] and was determined to be $121 \mathrm{mg} / \mathrm{L}$. The free ammonium level was determined to be $69 \mathrm{mg} / \mathrm{L}$ using a Rapid Ammonium kit from Megazyme (Bray, Ireland).

\subsection{Selection of Strains}

The yeasts of unknown identity isolated from vineyards belonging to Geisenheim University were initially isolated on YGCB agar plates $(5 \mathrm{~g} / \mathrm{L}$ yeast extract, $20 \mathrm{~g} / \mathrm{L}$ glucose, $0.2 \mathrm{~g} / \mathrm{L}$ chloramphenicol. $0.01 \mathrm{~g} / \mathrm{L}$ bromophenol blue, $2 \mathrm{~g} / \mathrm{L}$ agar). Sixty of these strains were plated on solid medium $(2 \mathrm{~g} / \mathrm{L})$ containing 50\% Muscaris grape must added to the agar after autoclaving and allowed to grow for two days at $25^{\circ} \mathrm{C}$. The agar plates were subjected to a "sniffing test" where eleven members of the Institute of Microbiology and Biochemistry at Geisenheim University surveyed the plates by conducting a simple olfactory inspection. Genomic DNA was isolated from six strains that exhibited an overall agreeable aroma to the panel. The genomic DNA was used to conduct an identification PCR test by amplifying the 5.8S-ITS (internal transcribed spacer) region using the ITS1 (TCCGTAGGTGAACCTGCGG) and ITS4 (TCCTCCGCTTATTGATATGC) primer pair. PCR products were purified using a sodium acetate/isopropanol method, and their respective DNA sequences were determined with StarSeq (Mainz, Germany) and were aligned using the program Muscle, which is included in MEGA version 5 [14].

\subsection{Micro-Vinification}

The three NSY yeasts were cultivated overnight in $100 \mathrm{~mL}$ YPD $(10 \mathrm{~g} / \mathrm{L}$ yeast extract, $20 \mathrm{~g} / \mathrm{L}$ peptone, $20 \mathrm{~g} / \mathrm{L}$ glucose) at $30^{\circ} \mathrm{C}$. The cells were harvested and then resuspended in $100 \mathrm{~mL}$ autoclaved Muscaris must and cultivated overnight. Approximately $1 \times 10^{7}$ cells $/ \mathrm{mL}$ (determined with a hemocytometer) were used to inoculate $220 \mathrm{~mL}$ of Muscaris must (only pasteurized) in a $250 \mathrm{~mL}$ wine bottle capped with an airlock and incubated at $22^{\circ} \mathrm{C}$. The same preculture procedure was followed with S. cerevisiae Vin 13 (a widely used commercial wine yeast from Anchor Yeast, Cape Town), which was aseptically added to wine bottles after three days at a concentration of $1 \times 10^{6}$ cells $/ \mathrm{mL}$. Fermentations were deemed 
finished once no weight-loss was recorded over a 24-hr period. Cells were removed via centrifugation and wine samples were stored at $4{ }^{\circ} \mathrm{C}$ prior to analysis.

\subsection{HPLC-Analysis}

To determine the initial concentration of the main sugars and acids of the grape must as well as the final concentrations of the major metabolites in the wine, high-performance liquid chromatography (HPLC) was employed using a modified method described previously [15]. An Agilent Series 1100 HPLC, equipped with a binary pump, an autosampler, a multi-wavelength detector (MWD) and a refractive index (RI) detector (Agilent Technologies, Steinheim, Germany) was used. An Allure Organic Acids column (Restek, Bad Homburg v. d. Höhe, Germany) with a particle size of $5 \mu \mathrm{m}$, an inside diameter of $4.6 \mathrm{~mm}$ and a column length of $250 \mathrm{~mm}$ was used. The MWD was set at a wavelength of $210 \mathrm{~nm}$ for the detection of organic acids and the RI was used for the detection of carbohydrates, organic acids and ethanol. The eluent used was water with $0.5 \%$ ethanol and $0.139 \%$ concentrated sulfuric acid. The flow rate was $0.6 \mathrm{~mL} / \mathrm{min}$ at a temperature of $46{ }^{\circ} \mathrm{C}$ (sugars, ethanol and organic acids) and $29^{\circ} \mathrm{C}$ (glycerol). The data was processed using Chemstation software (Agilent, Steinheim, Germany).

\subsection{Volatile Compound Analysis}

Wine samples of $5 \mathrm{~mL}$ each were subjected to headspace solid phase microextraction gas chromatography mass spectrometry (HS-SPME-GC-MS) analysis to assess the quantities of various aroma compounds. A GC 6890N was equipped with an MS 5977B (both Agilent, Santa Clara, CA, USA) and an MPS II robotic autosampler and CIS 4 (both Gerstel, Mülheim an der Ruhr, Germany). Ten microliters of an internal standard (1-octanol) was added to the wine sample and $1.7 \mathrm{~g}$ of $\mathrm{NaCl}$ was placed into a 20 -mL headspace vial. Solid-phase microextraction was carried out with a $65-\mu \mathrm{m}$ polydimethylsiloxane and divinylbenzol fiber (Supelco, Merck, Darmstadt, Germany). Aroma compound separation was performed using a $60 \mathrm{~m} \times 0.25 \mathrm{~mm} \times 1 \mu \mathrm{m}$ gas chromatography column (Rxi ${ }^{\circledR}-5 \mathrm{Si1}$, Restek, Bad Homburg v. d. Höhe, Germany) with helium used as a carrier gas. The sample was injected in split mode $\left(1: 10\right.$, initial temperature $30^{\circ} \mathrm{C}$, rate $12{ }^{\circ} \mathrm{C} / \mathrm{s}$ to $240{ }^{\circ} \mathrm{C}$, hold for $4 \mathrm{~min}$ ). The GC run started with an initial temperature of $40^{\circ} \mathrm{C}$ for $5 \mathrm{~min}$, then raised to $210{ }^{\circ} \mathrm{C}$ at $5{ }^{\circ} \mathrm{C} / \mathrm{min}$, and then raised again to $240^{\circ} \mathrm{C}$ at $20^{\circ} / \mathrm{min}$ and held for $10.5 \mathrm{~min}$. Mass spectral data were acquired in a range of mass to charge ratio $(\mathrm{m} / \mathrm{z})$ of 35 to 250 and used to derive concentration values. Calibrations were performed with a model wine $3 \%, 6 \%, 9 \%$ or $12 \%(v / v)$ solution of ethanol in water with the $\mathrm{pH}$ adjusted to $3 \mathrm{~g} / \mathrm{L}$ tartaric acid and the $\mathrm{pH}$ adjusted to 3.0). Terpene and norisoprenoid analysis were conducted as detailed previously [16].

\subsection{Statistical Analysis}

The fermentations were conducted in biological triplicates. All comparisons of the data generated from HPLC and GC-MS were made against the control (fermentations inoculate with Vin13 only) using One-way ANOVA with Dunnett's post-hoc test using GraphPad Prism version 5.00 for Windows, (GraphPad Software, San Diego, CA, USA).

\section{Results and Discussion}

\subsection{Strain Identification}

Six of the sixty strains tested via olfaction inspection were identified by the panel as imparting an overall pleasant aroma. Based on their 5.8S-ITS region two of the six strains that were identified as Debaryomyces hansenii, two as Metschnikowia pulcherrima, one as Candida railenensis and one as Nakazawaea ishiwadae (Figure 1). D. hansenii and M. pulcherrima strains are commonly isolated from wine milieus [5]. Since many coculturing attempts have been made with M. pulcherrima showing its utility in a coculturing must fermentation [17-19], it was decided to exclude it from further coculturing 
experiments. Despite a common member of the wine yeast population, $D$. hansenii strains have not been explored to a large extent in mixed-culture fermentations. Only one of the $D$. hansenii isolates were used for coculturing experiments as their ITS sequence were identical and it was assumed they would perform similarly.

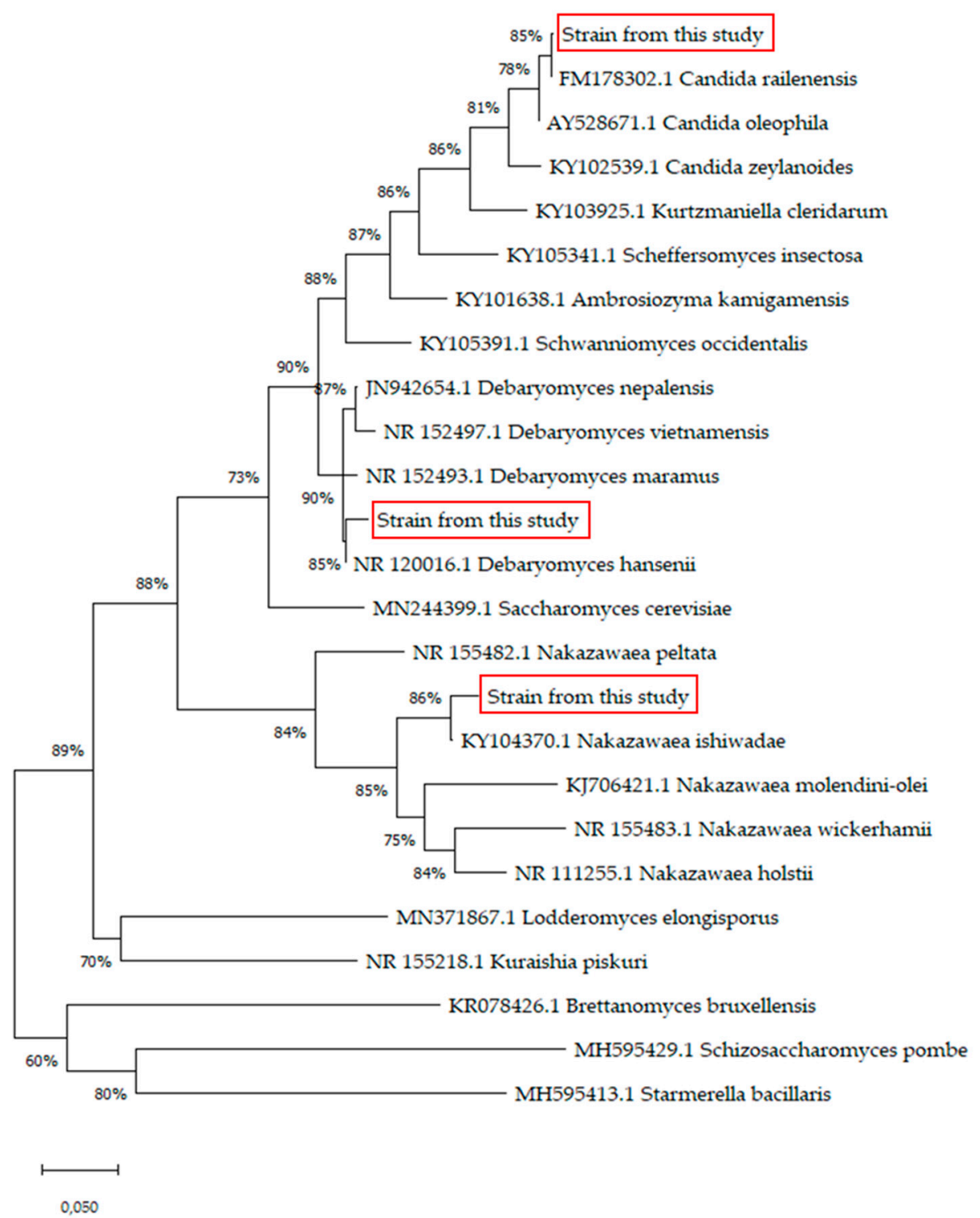

Figure 1. Maximum likelihood analysis showing the placement of the non-Saccharomyces species used in the study among common wine and closely related yeasts, including using their ITS1-5.8S-ITS2 region. The dendrogram was based on the general time reversible model $(\mathrm{GTR}+\mathrm{G}+\mathrm{I})$ as determined with MEGA 5.2 [14,20]. Bootstrap percentages from a 1000 bootstrap replicates are shown. Bar, $5 \%$ sequence divergence.

Although far less known, C. railenensis and N. ishiwadae have also been isolated from vineyards and wineries in previous studies [21-24]. N. ishiwadae has been tested in a mixed-culture fermentation in a synthetic must, showing an increased release of proteins into the wine [22]. C. railenensis was an initial candidate tested for increased thiol release from Sauvignon Blanc grape must [23], but, to the best of our knowledge, this is the first account of this yeast being used in a mixed-culture fermentation experiment. 


\subsection{Fermentation}

A sequential fermentation procedure was followed where the must was fermented for three days with the respective NSY culture before adding the S. cerevisiae Vin13 strain. No meaningful weight-loss was observed prior to the addition of Vin13. The NSY cultures also had little influence on the fermentation performance as there was no significant difference in the weight-loss profiles of the mixed-culture fermentations when compared to the control ferment inoculated with Vin13 only (Figure 2). Little to no difference in many of the oenological parameters in the mixed-culture fermentations was observed compared to the Vin13 control (Table 1). There was, however, a slight increase of approximately $20 \%$ in acetic acid levels with the mixed-culture fermentations with C. railenensis and D. hansenii. With $N$. ishiwadae, a $12 \%$ drop in glycerol levels was observed, although it did not correspond with an increase in ethanol levels as there was no significant modulation in ethanol levels. Although a minor acid in wine, there was a noteworthy reduction in the shikimic acid levels in the N. ishiwadae mixed-culture fermentation.

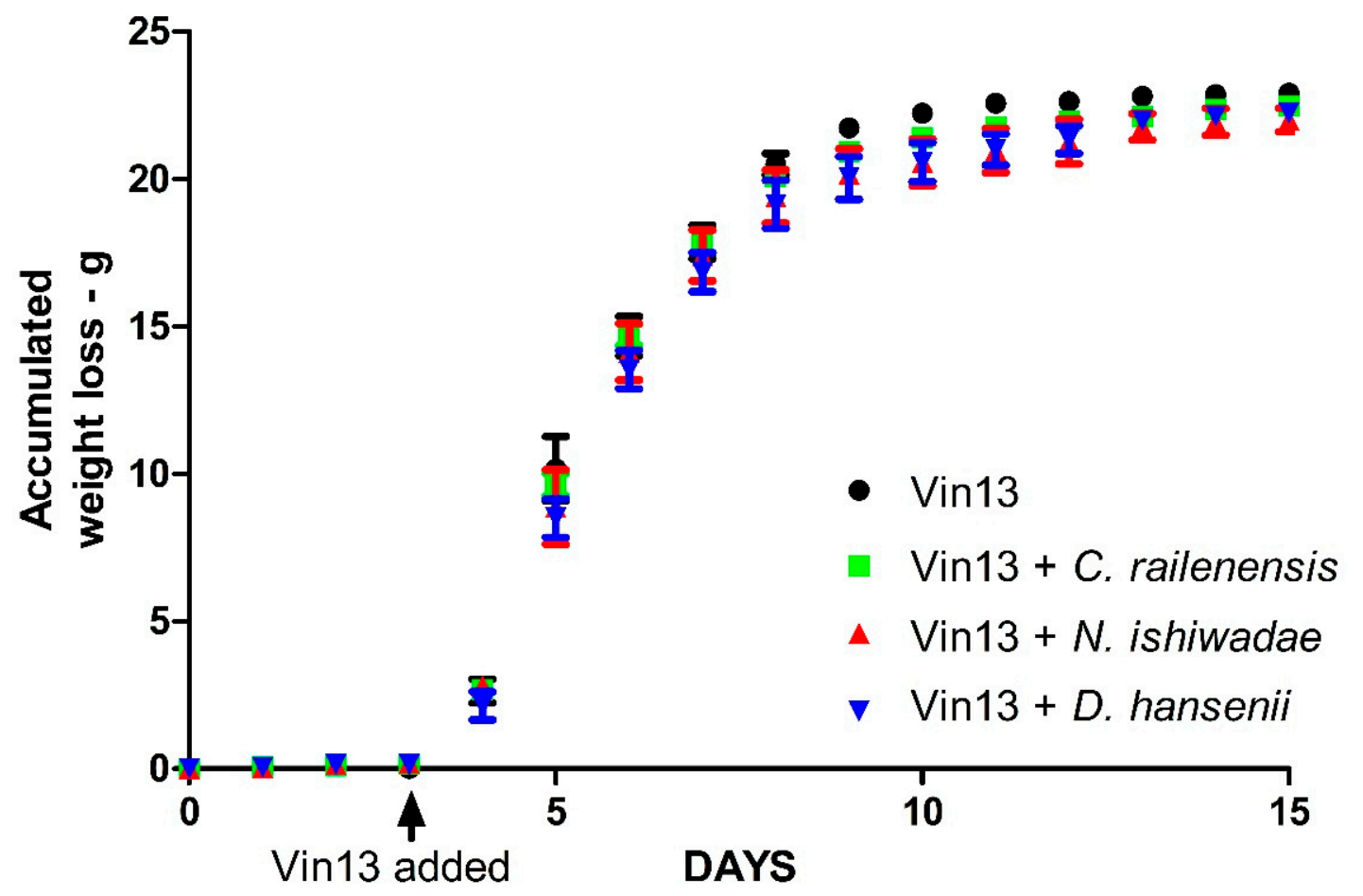

Figure 2. Fermentation kinetics measured as the daily accumulation of weight loss of the three mixed-culture fermentations conducted in triplicate. Error bars indicate the standard deviation. Once no weight loss was recorded over a period of one day, fermentations were considered finished.

\subsection{Volatile Composition}

There are two main ways by which yeast can impart flavor and aroma to a wine fermentation [25]. The first mechanism involves the production of aroma-active compounds that form part of a yeast's primary and secondary metabolism. The second mechanism is when a yeast strain produces enzymes like glycosidases or carbon-sulfur lyases that are capable of releasing aroma-active compounds from bound precursors present in grape must, which contribute toward the so-called varietal aroma. Using different of NSYs, previous coculturing experiments have demonstrated that NSY can impact both ways. This is especially the case with imparting increased varietal aromas, as many $S$. cerevisiae strains lack the enzymes needed for the release of volatile compounds from their bound moieties. 
Table 1. Analytical results of the main oenological parameters resulting from the mixed-culture fermentations.

\begin{tabular}{|c|c|c|c|c|c|c|c|c|c|}
\hline & $\begin{array}{l}\text { Residual } \\
\text { Sugars }\end{array}$ & $\begin{array}{l}\text { Tartaric } \\
\text { Acid }\end{array}$ & $\begin{array}{l}\text { Malic } \\
\text { Acid }\end{array}$ & $\begin{array}{l}\text { Acetic } \\
\text { Acid }\end{array}$ & $\begin{array}{l}\text { Citric } \\
\text { Acid }\end{array}$ & $\begin{array}{l}\text { Lactic } \\
\text { Acid }\end{array}$ & $\begin{array}{l}\text { Shikimic } \\
\text { Acid }\end{array}$ & Glycerol & Ethanol \\
\hline $\begin{array}{c}\text { Vin13 } \\
\text { (alone) }\end{array}$ & nd & $3.7 \pm 0.0$ & $3.1 \pm 0.0$ & $\begin{array}{c}0.42 \pm \\
0.0\end{array}$ & $\begin{array}{c}0.22 \pm \\
0.0\end{array}$ & $\begin{array}{c}0.18 \pm \\
0.0\end{array}$ & $\begin{array}{c}0.008 \pm \\
0.0\end{array}$ & $\begin{array}{c}6.97 \pm \\
0.1\end{array}$ & $\begin{array}{c}12.57 \pm \\
0.2\end{array}$ \\
\hline $\begin{array}{l}\text { Vin13 }(+C \\
\text { railenensis })\end{array}$ & nd & $\begin{array}{c}4.0 \pm \\
0.1^{* * *}\end{array}$ & $\begin{array}{l}3.1 \pm \\
0.0 \mathrm{~ns}\end{array}$ & $\begin{array}{c}0.51 \pm \\
0.0 * *\end{array}$ & $\begin{array}{c}0.21 \pm \\
0.0 \mathrm{~ns}\end{array}$ & $\begin{array}{c}0.17 \pm \\
0.0 \mathrm{~ns}\end{array}$ & $\begin{array}{c}0.008 \pm \\
0.0 \mathrm{~ns}\end{array}$ & $\begin{array}{c}6.90 \pm \\
0.1 \mathrm{~ns}\end{array}$ & $\begin{array}{c}12.73 \pm \\
0.3 \mathrm{~ns}\end{array}$ \\
\hline $\begin{array}{l}\text { Vin13 }(+N \\
\text { ishiwadae) }\end{array}$ & $2.4 \pm 0.1$ & $\begin{array}{l}4.0 \pm \\
0.1\end{array}$ & $\begin{array}{l}3.0 \pm \\
0.1 \mathrm{~ns}\end{array}$ & $\begin{array}{c}0.45 \pm \\
0.0 \mathrm{~ns}\end{array}$ & $\begin{array}{c}0.22 \pm \\
0.0 \mathrm{~ns}\end{array}$ & $\begin{array}{c}0.17 \pm \\
0.0 \mathrm{~ns}\end{array}$ & $\begin{array}{l}0.002 \pm \\
0.0 * * *\end{array}$ & $\begin{array}{l}6.20 \pm \\
0.1 * * *\end{array}$ & $\begin{array}{c}12.70 \pm \\
0.2 \mathrm{~ns}\end{array}$ \\
\hline $\begin{array}{c}\text { Vin13 }(+D \\
\text { hansenii) }\end{array}$ & $2.1 \pm 0.0$ & $\begin{array}{c}4.0 \pm \\
0.1 * * *\end{array}$ & $\begin{array}{l}3.0 \pm \\
0.1\end{array}$ & $\begin{array}{l}0.52 \pm \\
0.0 * *\end{array}$ & $\begin{array}{c}0.21 \pm \\
0.0 \mathrm{~ns}\end{array}$ & $\begin{array}{r}0.17 \pm \\
0.0 \mathrm{~ns}\end{array}$ & $\begin{array}{c}0.008 \pm \\
0.0 \mathrm{~ns}\end{array}$ & $\begin{array}{c}6.67 \pm \\
0.2 *\end{array}$ & $\begin{array}{c}12.53 \pm \\
0.2 \mathrm{~ns}\end{array}$ \\
\hline
\end{tabular}

All values in $\mathrm{g} / \mathrm{L}$ and are the average from a triplicate with the " \pm " sign indicating the standard deviation. (nd not detected; ns not significant; ${ }^{*} p<0.05 ;{ }^{* *} p<0.01$; ${ }^{* * *} p<0.001$ ). Boldface indicate significant values.

Upon assessing the volatile content in the wines derived from the mixed-culture fermentations, significant differences in the ester content (both acetate and ethyl ester) were observed compared to the Vin 13 control fermentation, as shown in Figure 3 and Table 2. With the N. ishiwadae coculturing, all the esters showed a marked increase compared to the Vin 13 control (a $24 \%$ increase in acetate esters minus ethyl acetate and a $42 \%$ increase in ethyl esters). A previous $N$. ishiwadae mixed-culture fermentation also showed an increase in the ester content [24]. The strain, on its own, did not finish the fermentation. For both C. railenensis (a $64 \%$ decrease in acetate esters and $49 \%$ decrease in ethyl esters) and $D$. hansenii (a $62 \%$ decrease in acetate esters and $21 \%$ decrease in ethyl esters) mixed-culture fermentations, a dramatic reduction in ester content was observed. Of note is that no hexyl acetate was detected in both $C$. railenensis and $D$. hansenii cocultures. The lower ester levels could be ascribed to enhanced esterase activity by these two strains that presumably hydrolyzed esters back to their respective higher alcohols. In a previous study, strong esterase activity was reported for a D. hansenii strain [26]. The hydrolysis of the acetate esters by esterases could also have contributed to the increased acetic acid found in wines derived from the C. railenensis and D. hansenii mixed-culture fermentations.

Muscaris is a fungus-resistant grape variety related to the aromatic Muscat variety with a high content of terpenes [27]. In Table 3, we show the concentrations of the terpenes and norisoprenoids in the final wines. The mixed-culture fermentations with $C$. railenensis and D. hansenii showed significantly higher levels of both versions of rose oxide, whereas $C$. railenensis coculturing also resulted in a 3.3-fold increase in citronellol levels. $D$. hansenii is known for its $\beta$-glucosidase activity, which is capable of releasing terpene compounds bound to sugar moieties, as has been previously demonstrated [28]. Little is known about the glycanases of $C$. railenensis. Interestingly, inexplicably lower levels of the two most common terpenes in Muscaris, namely hotrienol and $\alpha$-terpineol, were measured in the D. hansenii fermentation.
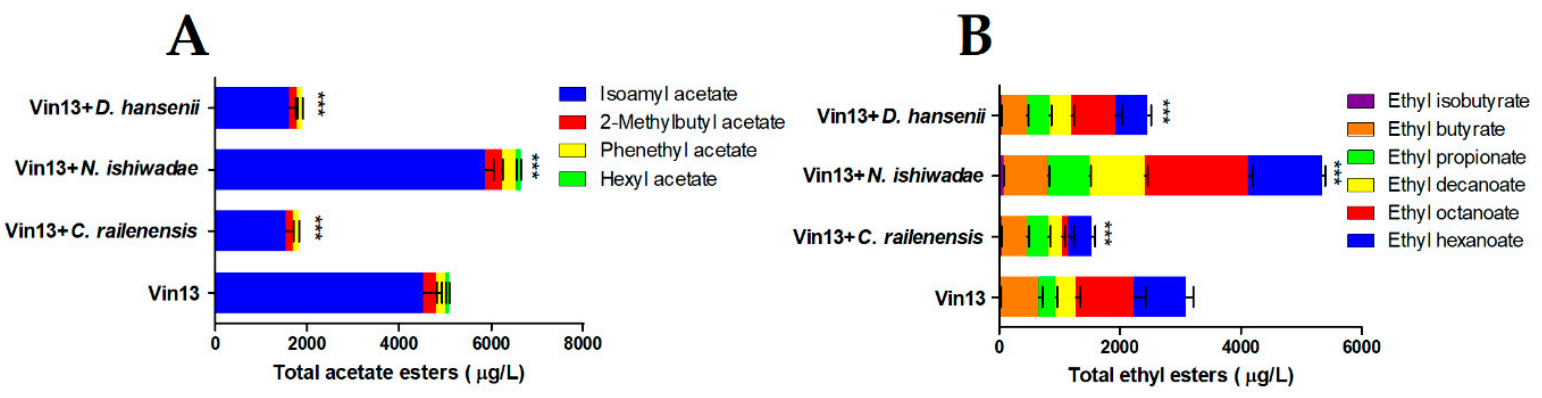

Figure 3. Sums of the (A) acetate esters (excluding ethyl acetate) and (B) ethyl esters in the final wines derived from the mixed-culture fermentations. Fermentations were done in triplicate. Error bar represents the standard deviation for each ester; ${ }^{* * *} p<0.001$. 
Table 2. Aroma volatiles in the final wines derived from the mixed fermentations as determined with GC-MS. Values are the average from a triplicate with the " \pm " sign indicating the standard deviation. The compounds 2-hydroxy-4-methylvaleric acid ethylester, succinic acid diethylester, benzeneacetic acid ethylester and 2-methylbutyric acid methylester were measured during the analysis, but were not detected in any of the samples. ns not significant ${ }^{*} p<0.05 ;{ }^{* *} p<0.01 ;{ }^{* * *} p<0.001$. Boldface indicate significant values.

\begin{tabular}{|c|c|c|c|c|c|}
\hline & $\begin{array}{c}\text { Aroma } \\
\text { Descriptor }\end{array}$ & $\begin{array}{l}\text { Vin13 } \\
\text { (alone) }\end{array}$ & $\begin{array}{l}\operatorname{Vin} 13(+C . \\
\text { railenensis) }\end{array}$ & $\begin{array}{l}\text { Vin13 }(+N . \\
\text { ishiwadae })\end{array}$ & $\begin{array}{c}\operatorname{Vin} 13(+D \\
\text { hansenii) }\end{array}$ \\
\hline$\beta$-myrcene & Pepper, spicy & $6.47 \pm 1.8$ & $6.09 \pm 1.9 \mathrm{~ns}$ & $6.58 \pm 2.1 \mathrm{~ns}$ & $3.98 \pm 3.5 \mathrm{~ns}$ \\
\hline limonene & Citrus, orange & $1.10 \pm 0.1$ & $1.02 \pm 0.2 \mathrm{~ns}$ & $1.06 \pm 0.1 \mathrm{~ns}$ & $1.12 \pm 0.1 \mathrm{~ns}$ \\
\hline cis-rose oxide & Rose & $1.05 \pm 0.0$ & $2.11 \pm 0.2 * * *$ & $1.24 \pm 0.0 \mathrm{~ns}$ & $1.92 \pm 0.1 * * *$ \\
\hline trans-rose oxide & Rose & $0.29 \pm 0.0$ & $0.56 \pm 0.0 * * *$ & $0.34 \pm 0.0 \mathrm{~ns}$ & $0.51 \pm 0.0 * * *$ \\
\hline cis-linalool oxide & Floral & $83.20 \pm 4.5$ & $75.70 \pm 3.4 n s$ & $77.18 \pm 2.6 n s$ & $80 \pm 8.5 \mathrm{~ns}$ \\
\hline trans-linalool oxide & Floral & $42.29 \pm 1.8$ & $37.74 \pm 2.2 n s$ & $41.86 \pm 1.5 \mathrm{~ns}$ & $39.63 \pm 4.8 \mathrm{~ns}$ \\
\hline nerol oxide & Green, herbal & $12.82 \pm 0.1$ & $12.93 \pm 0.7 \mathrm{~ns}$ & $11.11 \pm 0.2 *$ & $12.62 \pm 0.8 \mathrm{~ns}$ \\
\hline vitispirane & Floral, fruity & $0.62 \pm 0.0$ & $0.60 \pm 0.0 *$ & $0.61 \pm 0.0 \mathrm{~ns}$ & $0.66 \pm 0.0 * *$ \\
\hline linalool & Floral, rose & $75.00 \pm 1.3$ & $85.55 \pm 4.8 *$ & $78.63 \pm 0.4 \mathrm{~ns}$ & $84.12 \pm 4.6 *$ \\
\hline hotrienol & Sweet, tropical & $148.40 \pm 1.1$ & $160.20 \pm 9.1 *$ & $140.1 \pm 4.2 \mathrm{~ns}$ & $101.4 \pm 7.5 * *$ \\
\hline$\alpha$-terpineol & Pine, terpene & $220.60 \pm 5.5$ & $238.60 \pm 17.2 \mathrm{~ns}$ & $217.3 \pm 9.4 n s$ & $153.6 \pm 11.5 * * *$ \\
\hline citronellol & Floral, citrus & $2.34 \pm 0.6$ & $7.80 \pm 0.3^{* * *}$ & $5.49 \pm 1.2 * *$ & $3.82 \pm 0.4 \mathrm{~ns}$ \\
\hline$\beta$-damascenone & Fruity, floral & $0.79 \pm 0.0$ & $1.00 \pm 0.1 * *$ & $1.04 \pm 0.0 * *$ & $0.90 \pm 0.1 \mathrm{~ns}$ \\
\hline
\end{tabular}

Table 3. Terpene and norisoprenoid composition of the Muscaris wines derived from the mixed-culture fermentations as determined with GC-MS.

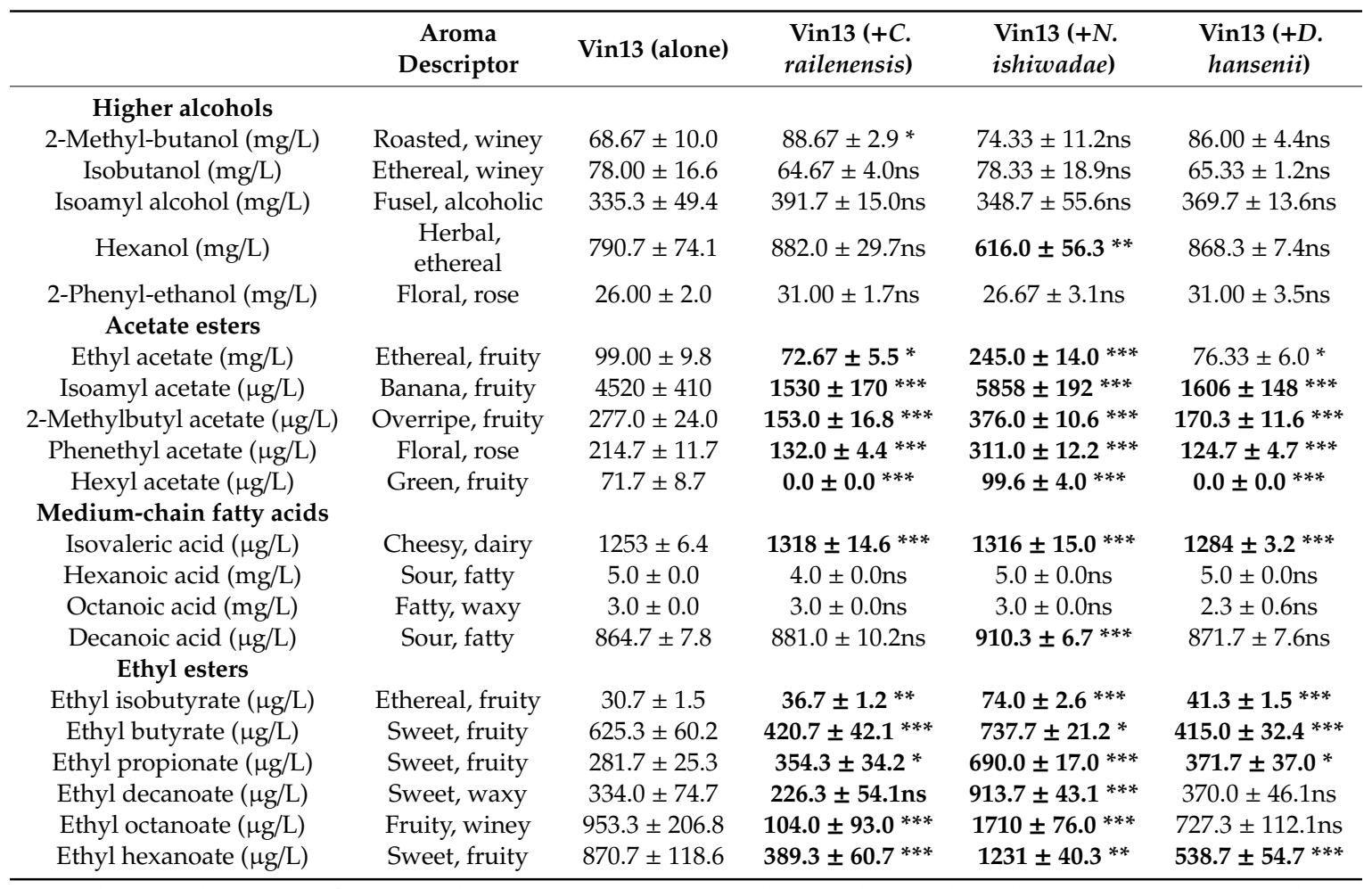

Values are the average from a triplicate with the " \pm " sign indicating the standard deviation. $\beta$-ionone, nerol, myrtenol, 1,1,6-trimethyl-1,2-dihydronaphthalene (TDN) and 1,8 cineol were also measured but were either not quantifiable or detectable in any of the samples. All concentrations in $\mu \mathrm{g} / \mathrm{L}$. (ns not significant ${ }^{*} p<0.05 ;{ }^{* *} p<0.01$; $\left.{ }_{* * *} p<0.001\right)$. Boldface indicates significant values.

\section{Conclusions}

We have tested the possible oenological gain of three NSYs not often explored in mixed-culture grape must fermentation. Although both C. railenensis and D. hansenii showed an increased release of 
certain terpenes and norisoprenoids, it was the cofermentation with $N$. ishiwadae that showed the most potential, as a notable increase in many ethyl and acetate esters was obtained. Overall, esters impart a pleasant fruity and flowery aroma to a wine and are often desired in young wines. Thus, a higher level of esters would add to the complexity of the wine, although this claim awaits confirmation through sensory analysis. If this observation of coculturing can be repeated with different musts and on a larger scale, this reasonably unknown yeast with no representative whole genome sequence currently available could be included on a list of important NSY starter cultures that are commercially available.

Author Contributions: Conceptualization, N.v.W., C.v.W.; methodology, N.v.W.; resources, C.v.W.; data curation, N.v.W.; writing—original draft preparation, N.v.W.; writing—review and editing, N.v.W., C.v.W., I.S.P.; supervision, C.v.W., I.S.P.; funding acquisition, C.v.W., I.S.P. All authors have read and agreed to the published version of the manuscript.

Funding: The authors thank Geisenheim University and Macquarie University for cofunding of this project and NvWs research fellowship. ISP is a team member in the Macquarie-led national Centre of Excellence in Synthetic Biology funded by the Australian Government thorough its agency, the Australian Research Council. The authors would like to thank the Hessen State Ministry of Higher Education, Research and the Arts for the financial support within the Hessen initiative for scientific and economic excellence (LOEWE) in the framework of AROMAplus (https://www.hs-geisenheim.de/aromaplus).

Acknowledgments: Heike Semmler (HPLC), Silvia Brezina (GC-MS), Stefanie Fritsch (GC-MS) and Judith Muno-Bender (Nitrogen measurements) are thanked for the technical assistance. Christine Schlering is thanked for providing the Muscaris grape must.

Conflicts of Interest: The authors declare no conflict of interest.

\section{References}

1. Christ, E.; Kowalczyk, M.; Zuchowska, M.; Claus, H.; Löwenstein, R. An exemplary model study for overcoming stuck fermentation during spontaneous fermentation with the aid of a Saccharomyces triple hybrid. J. Agric. Sci. 2015, 7, 8. [CrossRef]

2. Borneman, A.R.; Forgan, A.H.; Kolouchova, R.; Fraser, J.A.; Schmidt, S.A. Whole genome comparison reveals high levels of inbreeding and strain redundancy across the spectrum of commercial wine strains of Saccharomyces cerevisiae. G3 2016, 6, 957-971. [CrossRef] [PubMed]

3. Comitini, F.; Capece, A.; Ciani, M.; Romano, P. New insights on the use of wine yeasts. Curr. Opin. Food Sci. 2017, 13, 44-49. [CrossRef]

4. Ciani, M.; Comitini, F.; Mannazzu, I.; Domizio, P. Controlled mixed culture fermentation: A new perspective on the use of non-Saccharomyces yeasts in winemaking. FEMS Yeast Res. 2010, 10, 123-133. [CrossRef] [PubMed]

5. Jolly, N.P.; Varela, C.; Pretorius, I.S. Not your ordinary yeast: Non-Saccharomyces yeasts in wine production uncovered. FEMS Yeast Res. 2014, 14, 215-237. [CrossRef] [PubMed]

6. Van Wyk, N.; Grossmann, M.; Wendland, J.; Von Wallbrunn, C.; Pretorius, I.S. The whiff of wine yeast innovation: Strategies for enhancing aroma production by yeast during wine fermentation. J. Agric. Food Chem. 2019, 67, 13496-13505. [CrossRef]

7. Pretorius, I.S.; van der Westhuizen, T.J.; Augustyn, O.P.H. Yeast biodiversity in vineyards and wineries and its importance to the South African wine industry. S. Afr. J. Enol. Vitic. 1999, 20, 61-74. [CrossRef]

8. Barata, A.; Malfeito-Ferreira, M.; Loureiro, V. The microbial ecology of wine grape berries. Int. J. Food Microbiol. 2012, 153, 243-259. [CrossRef]

9. Shi, W.; Wang, J.; Chen, F.; Zhang, X. Effect of Issatchenkia terricola and Pichia kudriavzevii on wine flavor and quality through simultaneous and sequential co-fermentation with Saccharomyces cerevisiae. LWT Food Sci. Technol. 2019, 116, 108477. [CrossRef]

10. Kim, D.H.; Hong, Y.A.; Park, H.D. Co-fermentation of grape must by Issatchenkia orientalis and Saccharomyces cerevisiae reduces the malic acid content in wine. Biotechnol. Lett. 2008, 30, 1633-1638. [CrossRef]

11. Medina, K.; Boido, E.; Fariña, L.; Gioia, O.; Gomez, M.E.; Barquet, M.; Gaggero, C.; Dellacassa, E.; Carrau, F. Increased flavour diversity of Chardonnay wines by spontaneous fermentation and co-fermentation with Hanseniaspora vineae. Food Chem. 2013, 141, 2513-2521. [CrossRef] [PubMed] 
12. Rojas, V.; Gil, J.V.; Piñaga, F.; Manzanares, P. Studies on acetate ester production by non-Saccharomyces wine yeasts. Int. J. Food Microbiol. 2001, 70, 283-289. [CrossRef]

13. Dukes, B.C.; Butzke, C.E. Rapid determination of primary amino acids in grape juice using an o-phthaldialdehyde/N-acetyl-L-cysteine spectrophotometric assay. Am. J. Enol. Vitic. 1998, 49, 125-134.

14. Tamura, K.; Peterson, D.; Peterson, N.; Stecher, G.; Nei, M.; Kumar, S. MEGA5: Molecular evolutionary genetics analysis using maximum likelihood, evolutionary distance, and maximum parsimony methods. Mol. Biol. Evol. 2011, 28, 2731-2739. [CrossRef] [PubMed]

15. Schneider, A.; Gerbi, V.; Redoglia, M. A rapid HPLC method for separation and determination of major organic acids in grape musts and wines. Am. J. Enol. Vitic. 1987, 38, 151-155. Available online: https://www.ajevonline.org/content/ajev/38/2/151.full (accessed on 6 May 2020).

16. Kanter, J.P.; Benito, S.; Brezina, S.; Beisert, B.; Fritsch, S.; Patz, C.D.; Rauhut, D. The impact of hybrid yeasts on the aroma profile of cool climate Riesling wines. Food Chem. X 2020, 5, 100072. [CrossRef] [PubMed]

17. Ruiz, J.; Belda, I.; Beisert, B.; Navascués, E.; Marquina, D.; Calderón, F.; Rauhut, D.; Santos, A.; Benito, S. Analytical impact of Metschnikowia pulcherrima in the volatile profile of Verdejo white wines. Appl. Microbiol. Biotechnol. 2018, 102, 8501-8509. [CrossRef]

18. Varela, C.; Barker, A.; Tran, T.; Borneman, A.; Curtin, C. Sensory profile and volatile aroma composition of reduced alcohol Merlot wines fermented with Metschnikowia pulcherrima and Saccharomyces uvarum. Int. J. Food Microbiol. 2017, 252, 1-9. [CrossRef]

19. Barbosa, C.; Lage, P.; Esteves, M.; Chambel, L.; Mendes-Faia, A.; Mendes-Ferreira, A. Molecular and phenotypic characterization of Metschnikowia pulcherrima strains from Douro Wine Region. Fermentation 2018, 4, 8. [CrossRef]

20. Kumar, S.; Stecher, G.; Li, M.; Knyaz, C.; Tamura, K. MEGA X: Molecular Evolutionary Genetics Analysis across Computing Platforms. Mol. Biol. Evol. 2018, 35, 1547-1549. [CrossRef]

21. Brysch-Herzberg, M.; Seidel, M. Yeast diversity on grapes in two German wine growing regions. Int. J. Food Microbiol. 2015, 214, 137-144. [CrossRef] [PubMed]

22. Cioch-Skoneczny, M.; Satora, P.; Skotniczny, M.; Skoneczny, S. Quantitative and qualitative composition of yeast microbiota in spontaneously fermented grape musts obtained from cool climate grape varieties 'Rondo' and 'Regent'. FEMS Yeast Res. 2018, 18, 1-11. [CrossRef] [PubMed]

23. Drumonde-Neves, J.; Franco-Duarte, R.; Lima, T.; Schuller, D.; Pais, C. Association between Grape Yeast Communities and the Vineyard Ecosystems. PLoS ONE 2017, 12, e0169883. [CrossRef] [PubMed]

24. Ruiz, J.; Ortega, N.; Martín-Santamaría, M.; Acedo, A.; Marquina, D.; Pascual, O.; Rozès, N.; Zamora, F.; Santos, A.; Belda, I. Occurrence and enological properties of two new non-conventional yeasts (Nakazawaea ishiwadae and Lodderomyces elongisporus) in wine fermentations. Int. J. Food Microbiol. 2019, 305, 108255. [CrossRef] [PubMed]

25. Belda, I.; Ruiz, J.; Esteban-Fernández, A.; Navascués, E.; Marquina, D.; Santos, A.; Moreno-Arribas, M.V. Microbial contribution to wine aroma and its intended use for wine quality improvement. Molecules 2017, 22, 189. [CrossRef] [PubMed]

26. Besancon, X.; Ratomahenina, R.; Galzy, P. Isolation and partial characterization of an esterase (EC 3.1.1.1) from a Debaryomyces hansenii strain. Neth. Milk Dairy J. 1995, 49, 97-110.

27. Pedneault, K.; Provost, C. Fungus resistant grape varieties as a suitable alternative for organic wine production: Benefits, limits, and challenges. Sci. Hortic. (Amst.) 2016, 208, 57-77. [CrossRef]

28. Yanai, T.; Sato, M. Isolation and properties of beta-glucosidase produced by Debaryomyces hansenii and its application in winemaking. Am. J. Enol. Vitic. 1999, 50, 231-235.

(C) 2020 by the authors. Licensee MDPI, Basel, Switzerland. This article is an open access article distributed under the terms and conditions of the Creative Commons Attribution (CC BY) license (http://creativecommons.org/licenses/by/4.0/). 